\title{
DESDE LA GLOBALIZACIÓN HASTA LA CONFERENCIA DE ESTOCOLMO
}

\author{
FERNANDO DE ROJAS MARTÍNEZ-PARETS \\ Universitat d'Alacant-Universidad de Alicante
}

Nuestra opulenta y a la par desorientada sociedad tiene cuanto desea, excepto la capacidad de desear lo que de veras necesita.

De ahí su vergonzosa y oronda pobreza: para disponer de muchas cosas que no valen lo que cuestan destruye recursos que todavía no cuestan lo que realmente valen.

Disponemos de una rica sociedad moralmente empobrecida, porque rico es quien tiene lo que precisa, no quien tira cuanto desea.

\section{Ramón Folch. Naturalista catalán; de su libro "Que lo hermoso sea poderoso»}

Entiendo que lo más importante que tenemos entre manos, es implantar un sistema de manejo adecuado de nuestro Planeta. Sin ello lo verosímil es que no demos paso al relevo que nos viene detrás y desaparezcamos como especie. De las ciencias de la naturaleza aprendemos lo que se debe hacer, pero las ciencias sociales no dicen cómo. Quizás porque nuestros congéneres no quieren más que gratificaciones inmediatas o porque la tarea es desmesurada: asimilar los 12.000 millones de terrícolas que seremos en breve y compartir lo que tenemos. Las instituciones básicas de que hoy disponemos, el estado-nación y el mercado no valen para esto.

Ramón Martín Mateo. Director del Instituto del Agua y de las Ciencias Ambientales. Alicante. Del libro «Bosque de bosques»

Quan una espécie d'animal o planta desapareix per extinció, s'emporta amb ella lliçons de supervivéncia codificades en els seus gens, durament guanyades al llarg de milions d'anys d'evolució i adaptació.

L'extinció per a les espècies té el mateix astigma que la mort per a I'individu: és per sempre... No deixem que el nombre d'espècies extingides creixca més enllá del que és biológicament raonable i evolutivament necessari.

No permetem que els museus de zoologia $i$ els jardins botánics, que hui exposen esquelets i animals morts o plantes aclimatades pertanyents a especies vives, 
acaben essent inmensos mostraris de les faunes les flores que nosaltres mateixos haurem ajudat a extingir. Ens hi juguem també la nostra extinció.

Joandoménec Rós i Aragonés. Profesor de Ecología. De su libro «La nostra ecología de cada día»

Sumario: Introducción

Antecedentes: La percepción del entorno

Precedentes: La conscienciación medioambiental

Análisis: Diagnóstico del sistema global

La positivización del medio: La conferencia de Estocolmo

Texto de la conferencia de Estocolmo 1972

Bibliografía

\section{INTRODUCCIÓN.}

El medio ambiente cada día adquiere mayor importancia en nuestra sociedad y despierta una vertiente nueva en muchas ramas del saber. Este interés social e individual que se revela como idea necesaria para el presente y el futuro inmediato de nuestro mundo, así como la aparente novedad que supone el que en casi todas las disciplinas del conocimiento se estén conformando especializaciones relacionadas con el medio ambiente, a menudo olvida sus tiempos de génesis; el idealismo y la tensión que lo generó.

Hubo un tiempo no muy lejano en que algunas personas y movimientos sociales empezaron a plantearse, de forma a veces casi compulsiva, hacia dónde nos llevaba el sistema mundial en el que todos vivimos inmersos. Aquel tiempo en el que la amenaza de la destrucción nuclear, el ritmo frenético de producción y consumo que se expandía a velocidades hasta entonces nunca sospechadas así como la insostenibilidad de un sistema que condenaba a insalvables abismos de pobreza a un creciente tercer mundo, dio lugar a un movimiento de catastrofismo antropológico y ambiental que soñaba con restablecer el equilibrio humano y planetario.

Aquellos sueños y aquellos temores los hemos metabolizado y sirvieron para hacerse muchas preguntas y plantar las simientes de muchas conscienciaciones, personales siempre y colectivas a veces, por lo que no han muerto ni han sido absurdamente estériles.

Ahora que todo se tecnifica y se razona, en definitiva que medimos los riesgos, no debemos olvidar el espíritu y la inquietud que nos llevaron hasta este inicio del camino. 
En esta obra se ha pretendido recordar, aunque sea brevemente, el nacimiento remozado y la difusión popular de los ideales que nos acompañan hacia el siglo XXI; solidaridad, globalización, medio ambiente, calidad de vida, antibelicismo, humanismo, pluralidad. Todos ellos constituyen el magma de esa preocupación por el futuro de nuestra civilización, incluso de nuestra especie y de nuestro actual medio ambiente, que siempre estuvo ahí pero que particularmente hierve y se expande ante la insostenibilidad del modelo de crecimiento imperante.

Ante las evidencias, se concluye; el mundo y los países que lo integran tienen un futuro común, interrelacionado, que sobrepasa fronteras y que no puede continuar en la dinámica ciega y frenética en la que actualmente vive.

Es en este contexto en el que nace la Conferencia de las Naciones Unidas de Estocolmo de 1972, la primera carta que de manera global hace patente la preocupación mundial por el sistema de desarrollo y por el medio ambiente.

Antes de dedicarse, especializarse o preocuparse por la defensa del medio humano o por la conservación de la Naturaleza, debiéramos reflexionar y conocer estos pensamientos, estas corrientes y esta acta internacional que suponen sus orígenes más claros.

Jurídicamente en Estocolmo se comenzó la base de las grandes reuniones internacionales sobre el medio ambiente mundial que han tenido su continuidad en Río de Janeiro en 1992, pero también asentará una época en que los grandes bloques regionales como Europa toman para sí una política conjunta de protección ambiental.

Así pues, no ignoremos, aunque sea de manera esquemática, el esfuerzo, génesis e ideales del movimiento ambientalista y veamos el texto de Estocolmo no como una mera declaración de principios sino como el inicio de la consciencia global y del mandato de defensa del medio ambiente y el equilibrio social que se hace imprescindible atender en este final de siglo.

\section{ANTECEDENTES: LA PERCEPCIÓN DEL ENTORNO}

El hombre, en tanto género, pero sobre todo como individuo, en su capacidad de percepción y especialmente de sensibilidad, ha sentido -debe haber sentido- siempre, un impulso, una llamada añorante a menudo enfrentada a su progreso, ignorada y postergada, hacia su reintegración con la Naturaleza, tanto más cuanto el sistema que él mismo creaba iba produciendo complejas problemáticas y alienaciones.

En los valores, mitos y creencias del hombre primitivo la Naturaleza y sus elementos son en sí mismos divinidades, expresiones de la divinidad o intermediadores entre la realidad y lo sobrenatural. En las religiones antiguas de oriente la Naturaleza en sí constituye un círculo completo y complementado de lo divino con lo humano que de otra manera queda roto, incomprensible.

No es este sentido cíclico, integracionista, el de los grandes monoteísmos judeocristianos, (incluido el mahometano, y otras derivaciones religiosas del tronco gené- 
sico monoteístico) donde el ser humano es el elemento cumbre, dominador, el que legitima para su prosperidad al resto de la creación. ${ }^{1}$

Partiendo de tal antropocentrismo esta consciencia de sí mismo ha difundido entre el ser humano la idea de que su propio destino, su particular naturaleza, se hallaban fuera y por encima de la Naturaleza e incluso que su porvenir se debatía en parámetros diferentes a los del planeta en todo aquello que no fuera la progresiva instrumentalización de la misma Tierra como solar y proveedor del desarrollo del hombre. ${ }^{2}$

Como el profesor Martín Mateo señala así y todo, las modulaciones posteriores de estas religiones no dejan de aportar una interpretación responsabilizadora y equilibradora de la relación entre la obra divina y los hijos de Dios con posiciones naturalistas como las de San Francisco de Asís.

Será en Europa, con el surgimiento de los pensamientos racionalistas e ilustracionistas junto con el progreso de las ciencias cuando se dé, en cierta manera, el precedente más cercano de constitución de corrientes donde una cierta ecología, un cierta concepción de la Naturaleza, empieza a contraponerse a los primeros avances de la civilización industrial; es una reacción contra el dominio del orden y el artificio, la obra humana, por lo que pensamientos como los de Rousseau ${ }^{3}$ o Chateaubriand no son una filosofía del medio sino una reacción que los identifica más con lo que será típico del romanticismo; la vuelta a lo primitivo, a los escenarios agrarios o selvícolas, anhelo que se repetirá bien desde las filosofías naturalistas y colectivistas o con-

1 MARTÍN MATEO, Ramón. El hombre una especie en peligro. Capt. V. 2. Págs. 84 y 85. Edit. Campomanes Libros. Año 1993.

2 A este respecto solamente mencionar que el antropocentrismo constituye parte intrínseca y constante del pensamiento e incluso de las creencias occidentales desde tiempos clásicos, baste referirse a la Biblia o al entendimiento histórico griego del mundo cuyos mitos ya remiten a un antropomorfismo cuanto menos. Desde el punto de vista filosófico la cosmogonía aparece en el pensamiento clásico griego hacia el siglo VII A.C. con los órficos, que incluso hacen referencias al origen del mundo en el mar o el tiempo, pero ya desde Sócrates pero sobretodo desde los sofistas el hombre constituye el tema central del pensamiento clásico definiéndose inclusive la filosofía como «la retórica sobre el ser y los asuntos humanos». Igual ocurre desde Herodoto con el conocimiento histórico, en este último aspecto resulta interesante y muy accesible la breve obra de ROMERO, José Luis. De Herodoto a Polibio. Edit. Espasa. 1952.

ODUM, E. En; Ecología. Peligra la vida. Edit. B. $2^{\text {a }}$ Edición, 1995 Capt. «Dominio o Mayordomía» pág. 248 trata igualmente del mandato bíblico de dominio de la Tierra por el hombre en clave de una nueva interpretación.

3 GONZÁLEZ ALVAREZ, Aligel. Manual de Historia de la Filosofía. Editorial Gredos. Año 1957. Colección: Biblioteca Hispánica de la Filosofía Volumen II. Capt. II Arts. 4 y 5 . De aquí se detrae que la Ilustración asienta la filosofía del siglo XVIII en la razón como elemento único e independiente con existencia propia y al tiempo suprema. Al contrario del racionalismo anterior, la razón ilustrada aúna lo empírico con lo racional o recogiendo la cita que se reseña de Voltaire «la antorcha de la experiencia y el compás del matemático» creando una fuerza de conquista de la Naturaleza, de progreso sobre las cosas. Rousseau es el precursor del naturalismo en el que la bondad del hombre y sus circunstancias en estado natural se quebrantan en sociedad. Ya con el siglo XIX aparece el romanticismo y en su extremo contrario el materialismo científico. 
trariamente desde la óptica de los movimientos conservacionistas y científicos de finales del XIX que se toman como primeras referencias en los tratados ${ }^{4}$ que glosan las génesis de la preocupación medioambiental. Todo lo cual no deja de situarnos bien en concepciones sentimentales de un ser humano que busca proteger los entornos naturales que le impresionan o por el contrario investigar los recién descubiertos sistemas de la biología, pero sin plantear una alternativa viable que reconvierta y aborde el modelo occidental e industrializado y su civilización respecto del mundo. Podríamos incluso decir que se trata en muchos casos de sociedades cerradas, filantrópicas a veces, ajenas al sistema o de exclusivo «leit motiv» científico.

En cualquier caso, lo que sí va despuntando en la percepción de la sociedad en aquellos momentos de maquinismo y librecambismo, es, una progresiva sensibilización y mentalización de que la acción del hombre destruye parajes humanos y silvestres y que la Naturaleza tiene ciertos valores intrínsecos que deben ser salvaguardados de determinadas acciones y ambiciones humanas. Es por esto que se crean las primeras figuras de protección de espacios naturales, (los Parques Nacionales de Estados Unidos y posteriormente de Europa) y en el mundo anglosajón las primeras asociaciones activistas de carácter ecologista y conservacionista como la Sociedad Americana Sierra Club o la Sociedad de Ecología Británica. 5

Podríamos pues resumir este estadio que hemos llamado de antecedente o sobre la percepción del entorno en estos términos:

- El ser humano desde los tiempos antiguos se ha visto en la función de dominio del mundo y en la creencia de ser el centro o motivo de la creación.

- Las filosofías o corrientes de pensamiento que reaccionaban ante el fenómeno del desarrollo industrial no enjuician su rumbo sino que, más bien, quedan entre anhelos sensibles o motivaciones de investigación científica.

- La protección a la Naturaleza que nace de los Estados de ésta época es parcial (protección de parajes, medidas higienistas, etc.) aunque empieza a organizarse un movimiento conservacionista un tanto culto.

\section{PRECEDENTE: LA CONSCIENCIACIÓN MEDIOAMBIENTAL}

Será con la llegada del postindustrialismo, 6 en los umbrales de la década de los 60 cuando las consideraciones de tipo perceptivo, sensible, o las primeras resolucio-

4 En este sentido lo explica MARTÍN MATEO, Ramón, en su Tratado de Derecho Ambiental. Editorial Trivium. Año 1991, Volum. I. Capt. I: Fundamentos. Págs. 25, 26.

5 Idem. Págs. 26.27

6 Todavía no hay un término aceptado para designar la época tecnológica y económica nacida tras la II Guerra Mundial y que empieza a manifestarse plenamente en los 60, aquí empleamos la acuñada 
nes a los problemas sectoriales que ya van planteándose comienzan a transformarse en una consciencia más global, completa e interiorizada de la interdependencia que existe entre la sociedad humana y el medio ambiente, entre el porvenir del hombre y la Tierra.

Así, lo que se ha venido en llamar literatura ambientalista ${ }^{7}$ de los sesenta y principios de los setenta transforma esta sensibilidad de lo perceptible por una consciencia en la que hombre y medio constituyen una univocidad mundial, la cual se halla seriamente afectada hasta el punto de que nuestro modo de vida se halla gravemente comprometido, por lo que se achacó a esta corriente de alarmista y de padecer de un «pesimismo ecológico». 8

El clima desarrollista que siguió a la II Guerra Mundial así como la política competitiva y la carrera bélico-nuclear que se expandió ya por todo el mundo, hizo que este periodo histórico supusiera el de agresión más intensa y directa tanto al Medio como a la Humanidad, ${ }^{9}$ buscándose el potenciamiento tecnológico y la máxima internalización de beneficios de un sistema de crecimiento al que esta oleada de autores oponía un catastrofismo ambiental y humano que tenía su acogida entre las corrientes sociales de los años setenta que veían con bastante prevención el industrialismo desatado y sobretodo el peligro nuclear.

Así en la obra del filósofo Bertrand Russell ${ }^{10}$ se aprecia un alarmismo sobre la propia capacidad de la raza humana para comportarse con responsabilidad suficiente como para evitar la destrucción del planeta, señalándose que el aumento de nuestras capacidades -se refiere a las humanas- deviene principalmente de conocimien-

por el sociólogo Daniel BELL para referirse a una economía basada en los servicios. Aunque indudablemente en aquella década también se acuñaron otros términos como «postcivilización» por K. BOULDING 0 «sociedad tecnocrática» por ZBIGNIEW.

7 RUSSELL, Bertrand. Has Man a Future?. 1ª Edición 1961, Allen \&Unwin. Aquí empleamos la edición de Penguin Special.

CARSON, Rachel. Silent Spring. $l^{a}$ Edición 1962, Houghton Mifflin. Manejamos aquí la edición de 1991 de Penguin Books.

WARD y DUBOIS, Una sola Tierra (Just one Earth). 1972 Edita FCE.

TOFFLER. Alvin. Future Shock, $1^{a}$ Edición 1970. Empleamos la edición en castellano; El Shock del Futuro, 1973 de Plaza \& Janés.

Sociedad de Amigos de la Tierra, (F.O.E.), Sólo una Tierra. 1972.Editorial Vicens-Vives.Colec. Libros U, Ecología y Sociedad.

8 MARTín MATEO, Tratado de Derecho Ambiental. Editorial Trivium. Año 1991 Volum. I. Capt.1. Fundamentos. Págs. 31, 32. Este autor también señala un cierto catastrofismo en las conclusiones que aportan los estudios a cargo del Club de Roma en la página 13. de la Introducción a su libro $E l$ Hombre: una especie en peligro ya citado aquí. Este pesimismo también lo reseña en la Introducción al segundo informe del Club de Roma, en su versión española de 1975 Fernando de YBARRA LÓPEZ-DÓRIGA.

9 MARTÍN MATEO. Tratado de Derecho Ambiental. Vol. I. Capt. 11. Apt.II.3.2 Pág. 97.

10 RUSSELL, Bertrand Has Man A Future?. Ed. Penguin Special. 
tos adquiridos y transmitidos por la tradición y educación, siendo uno de los problemas de nuestro tiempo que nuestros hábitos y pensamientos no pueden cambiar tan aprisa como las técnicas. Es, en definitiva, el desfase entre el avance científico y tecnológico y la falta correlativa de una evolución social que propicie una asunción ordenada y consciente del potencial material de la humanidad. 11

Esta misma sensación de que el desarrollo corre fuera de control más que la propia capacidad de adaptación y asimilación del hombre y, por tanto, con objetivos propios y a veces excedentes a nuestra responsabilidad es observado como un auténtico problema por diferentes autores, incluso como una auténtica trampa para el ser humano. 12

A la percepción personal de degradación de nuestro entorno, de deterioro de determinados parámetros de nuestra calidad de vida (precisamente de aquellos que quedan fuera de los propios de mercado y consumo) que percibe la generación occidental de postguerra tal y como manifiesta en su análisis social Alvin Toffler en forma de auténtica falla psicológica (un «shock» de los individuos con un consumo y un cambio de hábitos atropellado, puramente mercantilista), se suma esta corriente de pensamientos sociológicos -y medioambientales- 13 que alimentando los movimientos convulsionadores de los 60 y 70 se llegó a constituir en una demanda política y social. ${ }^{14}$

Lo que en cualquier caso constituye una conclusión definitiva tanto para los que escriben y reflexionan sobre esta problemática, como para las diferentes corrientes de opinión o los foros científicos que analizan el desarrollismo reinante es que nos

11 MARTÍN MATEO, Ramón. El hombre: una especie en peligro. Edita Campomanes. Libros. Año, 1993.

12 TOFFLER, Alvin. El Shock del Futuro. Ed. Plaza \& Janés. Barcelona. 1973.

13 A la corriente que hemos referenciado como literatura ambientalista de la cual sólo hemos citado aquí algunas obras (5) y a las que cabría añadir otros autores de la misma como Dorst, Before Nature Dies, Udall; Quiet Crisis, Danscreau; Challenge for Survival, y otros tantos, hemos de añadir como colofón The Limits to Growth de MEADOWS, RANDERS y BEHRENS cuyas palabras a nuestro juicio resumen explícitamente el pensamiento medioambiental que como hemos dicho convulsionó las concepciones económico-desarrollistas de la época creando una demanda política que propició la Conferencia de Estocolmo de 1972: «Las necesidades y modos de vida de una población mundial siempre creciente que utiliza a tasa acelerada los recursos naturales disponibles, causa daños con frecuencia irreparables al medio y pone en peligro el equilibrio ecológico global» (pág. 11) «la conclusión a la que se llega es que la población y producción globales no pueden seguir creciendo indefinidamente" (pág.14). Límites del Crecimiento, Edición del Fondo de Cultura Económica 1972.

14 Así MARTÍN MATEO dice en Tratado de Derecho Ambiental pág. 15 respecto de la positivización de las demandas sociales en realidades político-administrativas y en normas, «El impulso que Ias convicciones morales transmiten, vía ideología formalizada, a los centros políticos de decisión, culmina con la materialización legal de reformas que aparecen como deseables al cuerpo social». En cualquier caso, simplemente recordemos la relación directa existente entre los planteamientos del Club de Roma y la Conferencia de Estocolmo. 
hallamos ante una situación de dimensiones y escala mundial que nada más puede ser eficazmente comprendida y solventada mediante medidas globales y por tanto desde escenarios internacionales. $Y$ es precisamente en este escenario donde se plantean las principales carencias de orden ${ }^{15} \mathrm{y}$ las barreras orgullosas de los nacionalismos estatales. A pesar del escollo del patrioterismo de los estados parece que la voluntad de una autoridad representativa a nivel mundial no es en si misma una quimera y sí una solución deseable y posible para hacer frente a los problemas estructurales mundiales que afectan al conjunto de los Pueblos, nacionalidades y regiones que requieren de una planificación y resolución globales como son la demografía el medio ambiente, la paz, la explotación y administración energética, etc. ${ }^{16}$

Nos encontramos pues en la época en que, desde una población afectada y conscienciada por el futuro humano y desde un grupo de pensadores, se empieza a asumir el proceso de globalización y la peligrosidad de determinadas políticas arriesgadas de la humanidad, sugiriéndose con mayor o menor realismo, vehemencia o espíritu confrontativo la limitación del desarrollo económico ante la disminución progresiva de los recursos y la escalada en el deterioro de los sistemas naturales.

15 RUSSELL, Bertrand Has Man a Future? Capt. 6 y 7. En sus consideraciones sobre un posible gobierno mundial.

MEADOWS y otros. Limits to Growth. Nueva York 1972. Empleamos la edición de 1972 del FCE. México. Pág. 13. En referencia a abordar los problemas desde una institución global como la ONU dice, «En el seno de las Naciones Unidas ( ... ) la visión del futuro de la humanidad no tiene hoy gran alcance. En lo político se carece de meta, los obstáculos para la paz están a la vista sin que las Naciones Unidas como tal sean capaz de removerlos» A pesar de esta desconfianza en la institución este informe del Club de Roma insiste en la globalidad de problemas y de sus soluciones.

LÓPEZ BUSTOS. Fco. Luis. La Organización Administrativa del Medio Ambiente. Universidad de Granada. Cuadernos Cívitas. 1992. «En el ámbito internacional no existe según cada Tratado, Convenio. Acuerdo, etc. sobre Medio Ambiente, un aparato internacional ni una organización administrativa específica que se ocupe de decidir, gestionar, vigilar o imponer sanciones en esta materia. Solamente pueden mencionarse organismos internacionales ya de carácter universal como las Naciones Unidas bilaterales desarrollan con carácter muy general competencias ambientales en los que hay mínimos esbozos administrativos que se traducen, por ejemplo, en comisiones o reuniones pero que regional o derivados de convenios y acuerdos multi o sin potestades punitivas por lo que consiguen que la eficacia se diluya».

16 RUSSELL, Bertrand. Has Man A future? Ed. Penguin Special. En el Capt. 6. «Condiciones a largo plazo para la supervivencia humana» cita al que fue Ministro de Defensa norteamericano Mr. MAC MILLAN respecto de la positiva viabilidad técnica, y la conveniencia política de un Gobierno Federativo Mundial y un Sistema Internacional de Justicia para garantizar la paz y estabilidad en el planeta.

También sobre esta conveniencia de llegar a un sistema global de acuerdo o gobernación en determinados aspectos se manifiestan MEADOWS, Denis L. en Limites del Crecimiento pág, 236, o MARTíN MATEO, Ramón. En Tratado de Derecho Ambiental. Vol. 1. págs. 20, 67, 203, 204.

También MARTÍN MATEO en El Hombre: Una especie en Peligro. Pág. 16. en que se refiere a la necesidad de «abrir jurídicamente al Estado por arriba para dar lugar a la intervención económica superior y por abajo para permitir la diversidad cultural (...) que le subyace» igualmente alude a la Unión Europea como elemento esperanzador. 
Podemos definir por tanto unos años de grave dinámica de desarrollo contra el medio ambiente pero también como un periodo ya de conscienciación ambiental de las sociedades:

- Se alcanzan unas dinámicas de desarrollo en casi todo el mundo excepcionales que, en cambio, constituyen un mapa de países ricos y pobres con diferencias crecientes y un Medio Ambiente maltratado.

- Se denuncia el modelo del desarrollismo, o al menos su ritmo, y se explica al Medio Ambiente como escenario y fuente limitada de la vida en todo el planeta.

- Crece una demanda de limitación o cambio de rumbo de las políticas bélicas, industrialistas, consumistas, etc. porque se estima amenazan la supervivencia del hombre actual.

\section{ANÁLISIS: DIAGNÓSTICO DEL SISTEMA GLOBAL}

Estas corrientes de opinión y otras equivalentes nacidas en un principio de la revulsión social de la década 17 y de la que se ha llamado, como ya vimos, «literatura ambientalista», se difundieron entre las sociedades industrializadas impulsando lo que hemos definido como demanda política y social.

Es por esto que pasamos de una literatura de conscienciación a una de análisis de la situación del desarrollo humano y el medio ambiente que intente encuadrar desde ópticas más o menos realistas, más o menos científicas, las primeras respuestas a estas preocupaciones sociales.

Si en el capítulo anterior vemos como se va declarando como elemento esencial la globalidad del problema, en los setenta se inicia una expansión de las comunicaciones que interconecta el planeta de manera decisiva. ${ }^{18}$ Es en esta progresiva interrelación de los países del mundo que se expresa la óptica de la globalización de las soluciones desde planteamientos científicos y técnicos. ${ }^{19}$

17 MARTíN MATEO, Ramón. Tratado de Derecho Ambiental. Págs. 27 a 29, refiere los movimientos de carácter juvenil principalmente a menudo con una carga contestataria que aparecen en Europa o en la Costa Oeste de EEUU. como los pacifismos, comandos ecologistas, movimiento hippy, etc.

18 Precisamente RUSSELL en la ya citada obra Has Man a Future? Capt. 7. «¿Porqué molesta la idea de un gobierno?» Alude como una de las facilidades para superar el insularismo de los Estados a las vías de comunicación. Ciertamente sabemos que en la actualidad el mundo de la interconexión y las comunicaciones ha sido el que ha tenido un mayor crecimiento acentuando la «consciencia planetaria» y la globalización de los problemas y sobretodo de los mercados, hasta tal punto que existe un fenómeno que se ha venido en llamar «efecto mariposa» en alusión a la interrelación de los sucesos en el mundo y que tanto afecta al mundo de la prensa, el arte, la política o la economía.

19 MEADOWS. Denis L. The Limits to Growth. Nueva York 1972. Trad. Cast. Edita; Fondo de Cultura Económica. México 1972. Prólogo. Pág. 27. «ningún país puede resolver sus propios problemas si antes no resuelve los que amenazan al sistema global». 
Es decir, los informes y las principales obras de tipo técnico que van a llegar para analizar el estado del medio humano y su estrategia de crecimiento económico y productivo lo hacen desde la concepción global, y señalan que no puede ser de otra manera el análisis pues nos encontramos con una situación de carácter mundial, no porque todos los países y regiones del mundo se hallen en igual situación (que como es obvio y confirmaremos más adelante no es así, sino de grandes y crecientes diferencias) sino precisamente por que la situación del hombre, el medio y el nivel de desarrollo es una tupida red de interdependencias y relaciones a escala planetaria.

Dentro de la nueva literatura que toma el relevo ya con un prisma y una intencionalidad científica destacará el Club de Roma ${ }^{20}$ asociación privada cuyo objeto fue precisamente el análisis social independiente y cuyos informes marcarán la sucesiva conscienciación y la actitud institucional dado el prestigio que alcanzaron

Precisamente lo que vienen a señalar desde el Club de Roma es la comprensión de la Tierra como un sistema cerrado y finito en el que la actividad económica debe evitar el derroche de recursos y elementos disponibles.

Así, desde los análisis de este club, se planteaba la limitación del crecimiento; tesis que, como señala el profesor Martín Mateo en su Tratado de Derecho Ambiental, no constituye una proposición nueva dentro de las teorías económicas, inclusive desde el liberalismo. ${ }^{21}$ Ya Malthus señalaba la gravedad y necesidad de

20 MEADOWS, Denis L. y otros. The Limits to Growth. Obra ya citada aquí con anterioridad y que constituye un estudio de la problemática mundial en el que diferentes miembros del Instituto Tecnológico de Massachusetts estructuran un modelo mundial en lo que se ha denominado «Primer Informe» para el Club de Roma. Según autodefine esta obra (pág. 13) «EI estudio del Club de Roma es ante todo un instrumento o método en que por medio de la técnica del análisis dinámico de sistemas se interrelacionan cinco géneros de variables; monto y tasa de incremento de la población mundial, disponibilidad y tasa de utilización de los recursos naturales del planeta, crecimiento del capital y la producción industrial, producción de alimentos y extensión de la contaminación mundial». También hemos manejado la versión francesa de este libro titulada Halte a la Croissance? editada en 1972 por Fayard, Collection Écologie ya que ésta recogía una introducción de Robert LATTES (miembro del Club de Roma) y un trabajo de Janine DELAUNAY sobre las motivaciones del Club y el semblante de sus miembros, bastante interesante y de la que carecía la versión en castellano.

MESAROVIC, M- y PESTEL L., La Humanidad Ante la Encrucijada; Segundo Informe Del Club de Roma Año 1974. Aquí hemos manejado la edición en castellano del Instituto de Estudios de Planificación.de 1975. Esta obra continua la línea de estudio del Primer Informe para el Club de Roma.

FRIENDS OF THE WORLD. ONU. La Conferencia de Estocolmo: Sólo una Tierra. Editorial Vicens-Vives. Libros U. Ecología y Sociedad. Año 1972.

21 MARTín MATEO, Ramón, en su Tratado de Derecho Ambiental. Vol. I. Pág. 41, cita en este mismo sentido expresado además de a MALTHUS: a TAMAMES, RICARDO o STUART MILL. Igualmente añade al propio John Maynard KEYNES por su obra Eassays In Persuation. Nueva York, 1936. por haber anticipado que la prevalencia del objetivo de la calidad de vida sobre el de desarrollismo productivo llegaría a producirse y transcribe de esta obra el siguiente párrafo: no está lejano el día en que los problemas económicos retrocederán a los asientos traseros que les corresponden, siendo ocupados o recuperados los principales por nuestros problemas, los problemas de la vida, las relaciones humanas, la creatividad, el comportamiento o la religión». 
abordar el problema demográfico en correlación con el de los recursos y el propio estado estacionado de crecimiento había sido sugerido también desde los economistas clásicos. Sin embargo, es desde la denuncia del punto de inflexión a que parecía se dirigía el actual desarrollo económico y productivo que realizan los miembros del Club de Roma cuando mayor presión viene a aliniarse del costado de la solución del crecimiento cero o al menos de la inmediata y contundente limitación del crecimiento, sobretodo en determinados parámetros.

Esta teoría del crecimiento en estado de equilibrio viene precedida en el capítulo del mismo nombre del libro Limits to Growth por la sentencia del economista Stuart Mill de que tal posibilidad no supone ningún tipo de estancamiento en la mejora del nivel de vida y el progreso humano 22 y define tal estado como una equilibración de las constantes de relación capital-población que es la misma que analiza el Club de Roma como supuesto de equilibrio para el desarrollo de la humanidad.

Averiguada por tanto la premisa de lo que constituye la solución del crecimiento cero, su antecedente teórico, su replanteamiento por el equipo del informe en cuestión del grupo de Roma, cabe ya que nos planteemos qué conclusiones extraen del modelo que para ellos elaboró el Instituto Tecnológico de Massachusetts y los datos recogidos y analizados. Por lo que paso a sintetizarlas: ${ }^{23}$

1. Debemos percatamos de las limitaciones cuantitativas del medio ambiente mundial y las graves consecuencias de nuestros comportamientos.

2. Dadas las actuales circunstancias ambientales y humanas nos hallamos cerca del punto crítico demográfico.

3. La brecha entre los países ricos y los subdesarrollados debe superarse o la tensión que la misma generaría a nivel mundial acabaría por devenir en insoportable.

4. Con el desarrollo global al ritmo actual y si se incorporan al mismo los países subdesarrollados el medio ambiente mundial no puede sostenerse y entraría en grave crisis.

5. La validez del estudio reside principalmente en su enfoque cuantitativo del problema y las fuentes.

6. Hacen falta nuevas ideas, enfoques alternativos y soluciones cada vez más pluridisciplinares.

7. La soluciones expuestas son inaplazables.

8. El esfuerzo requiere una cooperación y política asumida a nivel mundial pero principalmente desde los países desarrollados.

22 MEADOWS, Denis L. Limits to Growth. En su versión en castellano citada en anteriores referencias. Pág. 218.

23 Idem. Págs. 238 a 244. 
9. Paralizar el crecimiento no equivale a congelar el status económico ni el nivel de vida.

10. Toda esta situación requiere emprender un cambio de valores.

Los propósitos que se debe plantear la sociedad estable en sus nuevos campos de actividad constituye un punto intermedio de las políticas necesarias ${ }^{24}$ en su objetivo de conseguir las macrorregulaciones a nivel global del sistema social y productivo que, estimo, constituyó un preámbulo más accesible sin recurrir (pero no por ello sin justificarse) en predicciones más alarmistas, falibles y por tanto inestables y criticables 25 como han resultado posteriormente las predicciones del Club de Roma (pese a su innegable utilidad como motor de arranque de la regulación y atención internacional hacia el proceso de desarrollo en el mundo y hacia la situación del medio humano).

Pero decíamos anteriormente que había un alineamiento favorable al crecimiento cero, o cuanto menos a la limitación del crecimiento sobretodo de determinados parámetros, a partir del primer informe del Club de Roma; una de estas macrorregulaciones que ya hemos visto seria la del capital que equipararía la tasa de inversión a la de depreciación, otra sería la de uso de materias primas que reduciría los insumos de las mismas a favor de una nueva demanda de menos productos y más servicios que mejoraran la calidad de vida y también hacia el reciclaje, y finalmente las relativas al control de la demografía y al desequilibrio mundial entre países desarrollados y subdesarrollados.

Respecto del parámetro demográfico hemos de resaltar su importancia a la hora de afrontar la problemática desde una perspectiva global, es quizá un requisito previo y fundamental abordar el desfase que Malthus ya en sus tesis denunciaba de crecimiento geométrico de la población frente a un crecimiento aritmético de los recursos. ${ }^{26}$ Lo que resulta evidente es que las tendencias disparadas de crecimiento poblacional sobretodo del Tercer Mundo resultan físicamente difíciles de soportar, en este

24 Idem. Pág. 221. Donde relaciona algunos de los «descubrimientos» de la sociedad estable que ya hoy empiezan a constituir lo que yo denomino «políticas intermedias» del desarrollo sostenible como métodos de reducción de la contaminación, tasas eficientes de reciclaje, mayor durabilidad de los productos, energías alternativas, control natural de plagas, anticonceptivos, avances médicos, etc. y que con una importancia económica creciente cumplen su objetivo incardinándose al tiempo dentro del sistema.

25 Algunos de los autores consultados que manifiestan el pesimismo del que se acusó al CLUB DE ROMA vienen en este mismo sentido consignados en la referencia 8 del presente.

26 MARTÍN MATEO, Ramón. Tratado de Derecho Ambiental. Vol. I. Pág. 37 y siguientes. En su apartado sobre el neomalthusianismo cita estas viejas posiciones de MALTHUS sobre la demografía señalando que, si bien han sido objeto de objeciones científicas, cuentan con el respaldo de las teorías de Josué DE CASTRO que llama la atención sobre la desigual distribución de la riqueza entre la población a escala mundial y con la explícita defensa de GENDARME. La Pobreza de las Naciones. Edita B.O.E. Madrid 1967. Que insiste en el crecimiento progresivo de la población sobretodo entre los países subdesarrollados y la problemática que esto conlleva. 
mismo sentido el Informe del Club de Roma dice textualmente 27 «La conclusión a que se llega es que la población y producción globales no pueden seguir creciendo indefinidamente» y añade más adelante «las políticas de población deben desde ahora tender a reducir hacia fines del presente siglo la tasa de natalidad». Esto incide de nuevo en el presupuesto defendido por varios autores como el propio Keynes de que el verdadero problema del ambiente humano a escala planetaria es de orden - mejor dicho de desorden- social.

Volviendo al Tratado de Derecho Ambíental de Martín Mateo; en el mismo se señala que 28 entre los países del Tercer Mundo los incrementos de natalidad que duplican cada veinte años a la población acaban por ahogar cualquier intento de mejora del nivel de vida. Pero es más, nosotros añadimos desde un punto de vista egoísta ¿Qué pasaría entre los países desarrollados si el conjunto de la población mundial, incluidos los países subdesarrollados alcanzaran siquiera los umbrales que nosotros estimamos mínimos de nivel de vida? Los informes que ha ido lanzando el Club de Roma, por limitarnos a la fuente que hemos conocido y estudiado, ${ }^{29}$ nos responden estimo que claramente; desde el punto de vista de producción, salud ambiental y materias primas, el resultado sería inviable con los actuales parámetros.

Vemos pues, que si hasta ahora hemos hablado del ambiente como escenario finito y agotable de la vida y las actividades humanas, con toda una literatura e incluso unas tesis científicas y técnicas que nos lo han hecho así entender y aceptar, hemos ido progresivamente transcendiendo desde el mismo hacia el Medio Humano; entendido como el ambiente y el conjunto de parámetros que hacen posible unas ciertas condiciones de vida no sólo para el planeta Tierra sino también para el ser humano y su desarrollo sostenible.

La importancia del parámetro demográfico para el denominado Medio Humano nos lleva a otro elemento esencial ya citado aquí y que es constitutivo de toda una nueva política mundial de desarrollo y reparto de la riqueza que va incluso a constituir el punto de reflexión de la Comunidad Internacional a la hora de entender conjuntamente los problemas del genero humano y las naciones de la Tierra, nos referimos a la necesidad de superar el desequilibro entre Norte y Sur, entre países desarrollados y países subdesarrollados o en vía de desarrollo.

En este mismo sentido Víctor Urquidi en su prólogo "Allende el Año 2000" entiende: 30 «las naciones industrializadas que consumen la mayor parte de los recursos naturales del mundo en beneficio de una pequeña parte de la población marchan, casi ciegamente, hasta niveles de consumo material y deterioro físico que a la larga

27 MEADOWS, Denis L. Limits to Growth. Págs. 14 y 17.

28 MARTín MATEO, Ramón. Tratado de Derecho Ambiental Vol. I. Pág. 39.

29 MEADOWS, Denis, L. Limits to Growth. Págs. 17 y 18.

30 Idem. Pág. 12. Prólogo a la edición en castellano de URDIQUI. Víctor L. México 1972. 
no puede sostenerse. Las naciones de menor desarrollo, en las que viven casi dos tercios de los habitantes del globo, en que hay un punto de partida de grave deterioro ambiental y baja productividad tienen una escasa capacidad para alcanzar niveles medios de bienestar». Es de tal importancia el desequilibrio entre los países industrializados y el conjunto de los no desarrollados que ante la perspectiva de un enfriamiento de los niveles de producción y de estabilización de las economías de los desarrollados (por ejemplo Japón que parecía habérselo planteado) se crea una alarma y unas condiciones negativas para el lento proceso de recuperación de los países en vías de desarrollo ${ }^{31}$ que nos llevan a entender las desconfianzas que se manifiestan hacia cualquier política de reducción o de crecimiento limitado por parte de estos.

La importancia pues del equilibrio entre países es de tal importancia como señala Janine Delaunay ${ }^{32}$ que el tema de la superación de los desequilibrios es la que principalmente moviliza a los organismos internacionales (UNESCO, ONU, FAO, etc.)

Estos son pues, en resumen, los planteamientos y los retos que se han ido planteando a la sociedad internacional para el sostenimiento de nuestro Medio Humano. El que los pronósticos de aquellos estudios del Club de Roma en los años setenta no hayan sido exactos, o que, se haya criticado como excesivo el carácter predictivo con que pretendía concluir este grupo y la literatura que lo envolvió en nada altera el espíritu, bastante vigente, de la nueva mentalidad anti-desarrollismo y prosostenibilidad que forma parte ya de las planificaciones institucionales y las políticas de casi todo el mundo.

Una nueva corriente de valores que busca lo cualitativo y lo humano más que lo cuantitativo de los viejos mercados constituye el futuro y la postmodernidad ${ }^{33} \mathrm{y}$ los postulados de los $90^{34}$ han pasado de una preocupación genérica por el Medio Ambiente al análisis de las interrelaciones globales entre la actividad económica y el equilibrio ecológico del planeta. La consciencia ecológica ya no es priorativa de grupos sensibilizados ni de especialistas y constituye una prioridad, tanto para la opinión pública como para los gobiernos. Se sigue pensando que el consumo de recursos naturales y de emisiones contaminantes se ha sobrepasado ya. Con todo además, como señala Altvater se pone especial importancia al estudio de las causas del bloqueo del desarrollo de los países el sur, preocupación que se agrava con la integración al mercado de los antiguos países soviéticos.

31 Idem págs. 16 y 17.

32 DELAUNAY. Janine. «Enquête de Janine Delaunay. Pág. 22. en el libro Halte a la Croissance? Edita Fayard. 1972. Collection Écologie.

33 BALlesteros, Jesús. Postmodernidad: Decadencia o Resistencia. Tecnos. Madrid 1990.

34 ALTVATER, Elmar. El Precio del Bienestar. Münster (Alemania) 1992. Empleamos la edición en castellano que editó Edicions Alfons el Magnànim. València 1994. 
Por tanto cerramos un capítulo centrado en unas nuevas teorías con fundamentación científica que han diagnosticado, con bastante certeza y de forma generalmente aceptada por la comunidad internacional un estado de salud y unas problemáticas mundiales y regionales del Medio Ambiente, a su vez interconectado con lo que de manera más amplia se ha llamado el Medio Humano. Sintetizamos el diagnóstico en:

- Falta sincronizar e interconectar el conocimiento científico y el social. No puede existir avance en un campo sin un equilibrio en el otro.

- El sistema organizatorio estatal por si sólo no vale para un mundo de soluciones cada vez más interdependientes y necesitado de estabilidad.

- El Medio Humano y los recursos de la Tierra necesitan de una planificación global que substituya el desarrollismo por el crecimiento sostenible y elimine progresivamente los desequilibrios regionales.

\section{LA POSITIVIZACIÓN DEL MEDIO: LA CONFERENCIA DE ESTOCOLMO}

La regulación positiva de temas que afectan a nuestro entorno natural viene produciéndose desde antiguo, al fin y al cabo desde el viejo Derecho Romano se están regulando materias como las rústicas y agrarias que tienen incidencia directa en el medio ambiente. No es por tanto el caso fijarnos en las materias normadas que tienen trascendencia para el medio pues Derecho y Medio Ambiente son dos campos tan amplios que resulta difícil por el contrario comprender que no se afecten entre sí y que no impliquen casi a cualquier aspecto de nuestra vida y nuestro entorno.

Realmente hablar de una «Positivización del Medio Ambiente» con el referente puesto en la Conferencia de Estocolmo puede ser interpretado cuanto menos como un eufemismo o una garrafal inexactitud; se trata de señalar en realidad que tanto el derecho al medio ambiente como el derecho del medio ambiente o Derecho Ambiental, positivizados en textos legales que lo reconocen (Constituciones, Cartas, Leyes Fundamentales) o que lo constituyen como materia (legislaciones específicas sobre contaminación, espacios naturales, etc.) tienen una génesis similar a la de los llamados «Derechos Fundamentales» 35 es decir, una base ética, programática y declarativa que surge como Acuerdo, Manifestación o Declaración, en este caso de la Comunidad Internacional legalmente constituida. En este sentido cuando tratemos de la Conferencia de Estocolmo de 1972 de las Naciones Unidas sobre el Medio Humano estaremos asistiendo ya a una positivización del tema, ya que vamos a

35 No los confundamos con la categoría de los derechos públicos fundamentales que implican la relación entre el Estado y el ciudadano. 
entender como Peces-Barba ${ }^{36}$ que los derechos fundamentales así expresados «se consideran a la vez como valores o paradigmas de un derecho futuro y como derecho vigente positivo en unas sociedades determinadas que los convierten en normas y principios de su ordenamiento, superando así el antagonismo que podríamos considerar existe entre una visión lusnaturalista y una positivista sobre este tema». Además podemos entender como René Cassin, ex presidente de la Corte Europea de Derechos Humanos que, habría una categoría de derechos que serían absolutos (y que por tanto siempre han subyacido al ordenamiento) y que él cifra en «libertad de consciencia y el derecho a una vida digna»,37 pensemos que una vida digna requiere como indispensable un medio adecuado, cuanto más importante si nos referimos a una vida digna para nuestra especie o para la propia Vida, con mayúsculas.

Así pues, como antecedente del nuevo derecho al medio ambiente, las postulaciones y declaraciones universales -al igual que ocurrió para los derechos humanosforman parte del proceso de positivización del mismo, bien sea definiéndolo; dando los caracteres de su futura transposición a las normativas y legislaciones realmente positivas, bien sea ilustrando el camino de las normativas existentes, ${ }^{38}$ estos papeles se vienen reconociendo por ejemplo en este mismo sentido por la doctrina italiana a la Conferencia de Estocolmo respecto de su concepto amplio del Medio Ambiente. ${ }^{39}$

En la obra El Hombre; una especie en peligro, ${ }^{40}$ se reflexiona sobre la condición antropocéntrica que caracteriza al derecho; aunque entendamos el Derecho Ambiental como «el conjunto de normas que intentan asegurar las condiciones adecuadas para la vida» es cierto que no debemos olvidar que tanto el responsable como el receptor de tales reglas sólo puede ser el ser humano y que por tanto podríamos deducir que simplemente nos hallamos ante un derecho implícito de los llamados «del hombre». La Conferencia de Estocolmo lo que hace es añadir a ese Derecho del Hombre (el básico derecho a la vida) la necesidad de preservar y ordenar un medio que lo haga posible y adecuado. A este respecto la Declaración de Río de 1992 lo que parece es ir incluso un paso más adelante, reconociendo la naturaleza integral e interdependiente del planeta, ordenando una eficaz regulación del Medio Ambiente.

36 CASTAN TOBEÑAS, José. Los Derechos del Hombre, Edit. Reus, S.A. $3^{\text {a }}$ edición. Año 1985. Pág. 14. Citando a PECES-BARBA en este mismo sentido.

37 Cita de Idem. Pág. 19.

38 PRIEUR, Michele. Prólogo a la obra del CEOTMA-CIFCA Calidad de vida, Medio Ambiente y Ordenación del Territorio. Vol. I. Año 1982. Dirigida por FUENTES BODELÓN, en que dice textualmente. «Si existe un campo en el que los principios elaborados en el plano internacional hayan ejercido y aún puedan ejercer influencia directa en los derechos nacionales es precisamente el del Medio Ambiente».

39 Refiriéndose al Ambiente como objeto de Derecho; su concepto amplio. Revista de la Asociación de Derecho Ambiental Español, nº 1 (Enero de 1997). Pág. 50.

40 MARTÍN MATEO. Ramón. El Hombre; una especie en peligro, Págs. 89 y 90. 
Para una concepción jurídica reducida del Medio Ambiente la versión que utiliza la Conferencia de Estocolmo es demasiado amplia ${ }^{41}$ aunque es la definición denominada así «amplia», la que tiene mayor predicamento.

Preocupados por definir lo que será constitutivo del Derecho Ambiental; y pensando que excede a ser uno de los «derechos del hombre»; entrando en la categoría nueva de los derechos colectivos, de los que todos somos titulares, (tanto los Pueblos o Comunidades como finalmente la Humanidad en su conjunto) ${ }^{42}$ entendemos que se trata de autorregular nuestra incidencia sobre el medio a fin de salvaguardar la vida y disponer de un ambiente adecuado para el hombre y los otros seres.

Pero hemos dicho que la Conferencia de Río de Janeiro de 1992 ha supuesto el reconocimiento de la naturaleza integral de la Tierra: En la Conferencia de Estocolmo desde su lema «Una Sola Tierra» encontramos este mismo espíritu, y así, vemos, que en la misma, se manifiestan los principios del desarrollo integral como un problema vital al que había que abordar desde lo económico, lo social o lo ambiental de manera conjunta. Se apela al sentido de la solidaridad a escala internacional y mundial, y finalmente un tercer concepto, también en esta línea y que resultará fundamental de cara al futuro; el de los bienes comunes de la Humanidad que habrá que proteger colectivamente. 43

Así pues pensamos junto con Echechuri, Faletto y otros miembros del Centro Internacional de Formación en Ciencias Ambientales (CIFCA), que aunque queramos dotar al tema del Medio Ambiente de una especificidad, una concreción que nos permita tener sobre el mismo una definición disciplinar, lo importante, y por tanto lo que permite diferentes ópticas y concepciones, es que se trata de una cuestión ética sobre el modelo y el estilo de vida en que vamos a organizar nuestras sociedades para su mejor pervivencia. ${ }^{44}$

Ciertamente el Derecho lo hace el hombre y lo cumple sólo el hombre, además el ser humano es a la vez de sujeto, objeto de este derecho al ambiente en tanto tiene reconocido disîrutar del mismo, pero no es este un derecho privativo, individual, sino

41 MARTíN MATEO, Ramón. Tratado de Derecho Ambiental. Pág. 81. La definición amplia reconoce que además de la Conferencia de Estocolmo de 1972 es la que utiliza la legislación americana de 1969, o la de la Comisión Económica Europea, o la propia definición de la CEE (pág. 87). Así también la doctrina del Tribunal Constitucional español en Revista de la Asociación de Derecho Ambiental Español, $\mathrm{n}^{\circ} 1$ Enero (1997). Secc. Doctrina Pág. 49.

42 MARTÍN MATEO, Ramón. El Hombre; una especie en peligro. Pág. 128.

43 ECHECHURRI. Héctor. FALETTO, E. y otros. Diez Años Después de Estocolmo. Desarrollo, Medio Ambiente y Supervivencia. Edita CIFCA Madrid 1983. Pág. 110.

44 Idem, Pág. 18. Interpretamos lo que transcribe el párrafo $2^{\circ}$ en el sentido de que la cuestión ambiental en efecto no puede especificarse sin más pues alude a una preocupación mucho más amplia, la del modelo mundial de organización, sostenibilidad. etc. 
por encima de todo colectivo, de la especie humana, ${ }^{45}$ un derecho para garantizar su desarrollo y adecuada supervivencia, por lo que se propone proteger la Naturaleza, el medio del que el hombre es elemento y parte y sin la interdependencia de la cual no se concibe ni como individuo ni como especie su pervivencia.

A todo esto consideramos ¿qué es lo que afecta a este sistema, cual es la acción a regular? El desarrollo productivo desordenado de las sociedades humanas, por lo que, como acabamos de mencionar, el CIFCA entiende que se trata de instrumentar un modelo social que armonice y garantice la adecuada existencia del individuo, el colectivo social y el medio, 46 tres escalas que sólo pueden entenderse como ya definió la literatura ambientalista desde el ámbito global. Y esta misma concepción es la que se contiene en la Conferencia de Estocolmo de 1972.

¿Por qué establecemos en la Conferencia de Estocolmo de 1972 sobre el Medio Humano el punto de inflexión en la aparición del concepto del Medio Ambiente desde el punto de vista mundial?

Porque si bien el Derecho Ambiental tiene sus primeras manifestaciones como disciplina con objeto y preocupaciones propias, particulares respecto de la de las demás ramas del Derecho, principalmente dirigiéndose hacia problemas sectoriales concretos y desde el ámbito estatal, (y si no recordemos la National Environmental Policy Act de EE.UU) ${ }^{47}$ será únicamente a partir de la cita de Estocolmo cuando se plasme una concepción mundialmente asumida de toda la problemática del medio y el desarrollo en el planeta, involucrando de manera amplia a todos los actores internacionales y a todas las problemáticas que desde la literatura ambientalista habían ido manifestándose como reales problemas del modelo mundial imperante.

Realmente la primera vez que las Naciones Unidas se ocuparon del tema del Medio Ambiente fue en tomo a la Conferencia Científica sobre la Conservación y Utilización de Recursos celebrada en Lake Succes en 1949, pero aquella conferencia, si bien histórica, sólo trataba de la explotación de los recursos naturales (bos-

45 Es, según VASAK, K. la naciente generación de «derechos de la solidaridad o nuevos derechos humanos» de muy difícil articulación técnica y que requieren no sólo de las comunidades soberanas que hoy por hoy funcionan sino también o primariamente de las entidades internacionales que aspiran a través de pactos o recomendaciones promover las respuestas jurídicas a las nuevas necesidades de los pueblos y los seres humanos. «Le Droit international, de l'homme» en Revue des droits de l'homme. Vol. I. Perdone París, 1972. Siguiendo la cita de CASTAN, Ma Luisa. En Los Derechos del Hombre.

46 El problema ecológico - dice Ricardo MORAGAS en el prólogo a la edición en castellano de La Conferencia de Estocolmo: Sólo una Tierra. Edit. Vicens-Vives, 1972- «no se resolverá sólo con leyes, disposiciones o comisiones, sino que la esencia es ética, ya que afecta a los valores de nuestra forma de vida occidental».

47 MARTÍN MATEO. Ramón. Tratado de Derecho Ambiental. Vol. I. Pág. 30 dice que el Rubicón del Derecho Ambiental moderno cabe fijarlo cronológicamente en 1970 con la aprobación en EE.UU. de la National Environmental Policy Act que había sido precedida por normativas sectoriales como la Clean Water Act 1948, la Clean Air Act 1969 y varios eventos internacionales sobre problemáticas concretas. 
ques, caza, pesca, etc.) pero aún no trataba temas como la contaminación o la generación de residuos, que todavía no se consideraban preocupaciones apremiantes. ${ }^{48}$ Luego vinieron otras reuniones y acuerdos internacionales sobre problemas sectoriales como el Acuerdo Internacional para la Prevención de la Contaminación del Mar por Petróleo, Londres 1954, la creación de la Agencia Internacional de la Energía, 1956, la Conferencia Intergubernamental de Expertos para el Uso Racional de los Recursos de la Biosfera, UNESCO, París 1968, ${ }^{49}$ pero no será hasta Estocolmo cuando se trate a nivel mundial del problema del medio y el desarrollo como problemáticas de la humanidad. 50

La creciente preocupación por el crecimiento, por el desarrollismo occidental, como en las mejores teorías de la literatura ambiental y conforme a las tesis que recogían los informes del Club de Roma, no era únicamente un problema de producción y consumo internos de los países ricos, eran un problema global que atenazaba muy especialmente a los países en vías de desarrollo, y esto es también y sobretodo lo que refleja la Conferencia de Estocolmo desde su enunciado hasta su contenido, destapando el arma fundamental de la solidaridad, es decir de la necesidad de corregir los desajustes del modelo que acertadamente estaban denunciando los informes técnicos y las consciencias humanitarias, por esto Estocolmo marcó otra diferencia fundamental. 51

A la Conferencia de Estocolmo le precedió una resolución de la Asamblea General de la ONU que iniciaba los preparativos en 1968, así como unas reuniones previas en Praga y Ginebra el año anterior a la misma, ${ }^{52}$ pero sobretodo será a partir del que se llamó «Informe Founex sobre el Desarrollo y el Medio Ambiente Preparatorio de la Conferencia de Estocolmo» 53 cuando se introducen de manera constitutiva tanto la preocupación por parte de los países en vías de desarrollo porque el nuevo marco de enfriamiento desarrollista y las catástrofes de la contaminación no les dificultaran aún más su derecho al crecimiento, como las ideas de política ambiental a nivel internacional.

48 LÓPEZ BUSTOS. Fco. Luis La Organización Administrativa del Medio Ambiente. Universidad de Granada. Edita Cívitas, Colec; Cuadernos. Año 1992.

49 MARTín MATEO, Ramón. Tratado de Derecho Ambiental, Vol. 1. Pág. 30. que los cita como los eventos internacionales previos a la Conferencia de Estocolmo.

50 ECHECHURI, Héctor, FALETTO, E. y otros, citan en Diez años después de Estocolmo esto como lo que da auténtica novedad a la conferencia de 1972. (Pág. 16).

51 Esta misma idea es recogida y reiterada como fundamental en el libro de Diez años después de Estocolmo referido en la cita anterior.

52 Esto lo recoge el Tratado de Derecho Ambiental Vol. I. Pág. 30, varias veces citado.

53 Este informe y la introducción por el Secretario General de la Conferencia se puede consultar en la obra del CEOTMA-CIFCA «Calidad de Vida, Medio Ambiente y Ordenación del Territorio. Textos Internacionales» Vol. I. Edita MOPU 1983. Dirige FUENTES BODELÓN, Fernando, que ya hemos citado con anterioridad. 
Las palabras del Secretario General de la Conferencia, Maurice F. Strong revelan muy bien la consideración que se hace de la problemática «hasta recientemente el medio ambiente no ha llegado a convertirse en un problema público a escala global. Se presentó en primer lugar entre las sociedades altamente industrializadas en las que la preocupación se centró sobre las consecuencias adversas de prácticas variadas y tecnologías que han producido la prosperidad. (...) En este contexto no es de extrañar que se cuestione en los países en desarrollo la importancia de esta nueva preocupación sobre el medio ambiente en relación y comparación con sus prioridades urgentes de desarrollo». ${ }^{54}$ Igualmente en la carta de envío de informe de la comisión al secretario de la Conferencia se denuncia los efectos dañinos que el crecimiento descontrolado causa al ser humano, a su salud y al propio medio, al tiempo que se señala la pobreza como consecuencia grave de este sistema. ${ }^{55}$

Volviendo pues al propio texto de la Conferencia de Estocolmo de las Naciones Unidas sobre el Medio Humano de junio de 1972,56 se ha dicho que el mismo sirvió de motivación para la creación del Programa de las Naciones Unidas para el Medio Ambiente, la realidad es que al menos a partir de ella siguieron reuniones sobre temas conexos como; asentamientos humanos, Vancouver 1976, recursos hídricos, Mar del Plata 1977, desertificación, Nairobi 1977, y todos los posteriores informes y planes internacionales, e incluso regionales. 57

Para finalizar volveremos a insistir en la positivización del tema ambiental que también se consolida a partir de la Conferencia, baste solamente señalar que el propio Martín Mateo considera que caracterizándose el ordenamiento ambiental por su vocación universalista esta rama del Derecho cobra su impulso definitivo precisamente a partir de la declaración de Estocolmo y las sucesivas reuniones que la prosiguen, lo que suscita diferentes principios y declaraciones que aunque la mayor parte

54 Ídem. Introducción por el Secretario General de la Conferencia. Pág. 27.

55 Ídem. Págs. 28 y siguientes.

56 La Conferencia se halla publicada en infinidad de textos, panfletos, libros, etc. aquí por comodidad personal usamos siempre de la reproducción que de la misma hace el libro de AYÙS, Manuel A., BALLESTER, Rafael y CRESPO, Andrés, Apuntes de Derecho Ambiental, de Gráficas Díaz, s.l. Sant Vicent del Raspeig (Alicante) 1996 y que por lo demás constituye un práctico y sencillo manual.

57 Hay regiones más sensibilizadas hacia el tema ambiental y que incluso denotan alguna forma de esfuerzo por programar sus economías, su equilibrio y su crecimiento, no sé si por influencia de la Conferencia de Estocolmo, no sé si siguiendo las directrices de regionalización del Club de Roma, ni siquiera sé si previendo la superación de los gobiernos estatales como modelo político del futuro. En 1977 la Comisión de las Comunidades Europeas confecciona un informe sobre el Medio Ambiente en la CEE. L'État de I'environnement: Premier rapport COMMISION DES COMUNAUTÉS EUROPÉENNES. Luxemburgo, 1977. Edita CEE. El nivel de sensibilidad que en el mismo refleja M. Roy JENKINS, su presidente, sigue la línea del ambientalismo positivo. A pesar de todos los defectos achacables la Unión Europea es el bloque regional más predispuesto a seguir una política ambiental en algo comprometida. 
de las veces no pasen del carácter intencional no dejan de ser la base de los progresos que van consiguiéndose en esta disciplina. 58

Llegados a entender la importancia de la Conferencia de Estocolmo en el proceso de asunción efectiva por la Comunidad Internacional de las problemáticas ambientales, humanas y de desarrollo, así como su papel en la progresiva positivización de un ordenamiento que se basa en declaraciones universales que ilustran luego normativas estatales y nacionales, destacaremos como cierre este extracto ${ }^{59}$ de entre los 26 principios de la Conferencia:

- El hombre tiene derecho al disfrute de condiciones de vida adecuadas en un medio de calidad tal que le permita su bienestar y desarrollo suficientes, así como la obligación de conservarlo,

- Los recursos de la Tierra y sus ecosistemas deben preservarse mediante la ordenación y planificación. Debe ponerse fin a la contaminación y a la agresión por liberación energética de los ecosistemas,

- Es indispensable una labor de educación y conscienciación en la protección del ambiente y de información en cuanto a la defensa y situación del mismo.

- Deben fomentarse en todos los países, especialmente en los países en desarrollo el adelanto en los avances científicos que permitan superar las problemáticas ambientales y debe favorecerse el equilibrio entre países ricos y pobres evitando el subdesarrollo de estos últimos.

\section{LA CONFERENCIA DE ESTOCOLMO DE LAS NACIONES UNIDAS SOBRE EL MEDIO HUMANO}

Reunida en Estocolmo del 5 al 16 de junio de 1972 y atenta a la necesidad de un criterio y unos principios comunes que ofrezcan a los pueblos del mundo inspiración y guía para preservar y mejorar el medio humano.

Proclama que:

1.- El hombre es a la vez obra y artífice del medio que lo rodea el cual le da sustento material y le brinda la oportunidad de desarrollarse intelectual, moral,

58 MARTÍN MATEO, Ramón. Tratado de Derecho Ambiental. Vol. I pág. 16.

59 LAVILA RUBIRA, J.J, y MENÉNDEZ ARIAS, Ma José. Coordinadores de la obra Todo Sobre el Medio Ambiente. Edita Praxis. Barcelona 1996 y sobre cuyo extracto de los principios de la Conferencia además del propio texto de la Conferencia me he basado para sintetizar los cuatro puntos expuestos. 
social y espiritualmente. En la larga y tortuosa evolución de la raza humana en este planeta se ha llegado a una etapa en que, gracias a la rápida aceleración de la ciencia y la tecnología, el hombre ha adquirido el poder de transformar, de innumerables maneras y en una escala sin precedentes cuanto le rodea. Los dos aspectos del medio humano, el natural y el artificial, son esenciales para el bienestar del hombre y para el goce de los derechos humanos fundamentales, incluso el derecho a la vida misma.

2.- La protección y mejoramiento del medio humano es una cuestión fundamental que afecta al bienestar de los pueblos y al desarrollo económico del mundo entero, un deseo urgente de los pueblos de todo el mundo y un deber de todos los gobiernos.

3.- El hombre debe hacer constante recapitulación de su experiencia y continuar descubriendo, inventando, creando y progresando. Hoy en día, la capacidad del hombre de transformar todo lo que le rodea, utilizada con discernimiento, puede llevar a todos los pueblos los beneficios del desarrollo y ofrecerles la oportunidad de ennoblecer su existencia. Aplicado errónea o imprudentemente, el mismo poder puede causar daños incalculables al ser humano y a su medio. A nuestro alrededor vemos multiplicarse las pruebas del daño causado por el hombre en muchas regiones de la Tierra: niveles peligrosos de contaminación del agua, el aire, la tierra y los seres vivos; grandes trastornos del equilibrio ecológico de la biosfera; destrucción y agotamiento de recursos insustituibles y graves deficiencias, nocivas para la salud física, mental y social del hombre, en el medio por él creado, especialmente en aquel en que vive y trabaja.

4.- En los países en desarrollo, la mayoría de los problemas ambientales están motivados por el subdesarrollo. Millones de personas siguen viviendo muy por debajo de los niveles mínimos necesarios para una existencia humana decorosa, privadas de alimentación y vestido, de vivienda y educación, de sanidad e higiene adecuados. Por ello los países en desarrollo deben de dirigir sus esfuerzos al desarrollo, teniendo presentes sus prioridades y la necesidad de salvaguardar y mejorar el medio. Con el mismo fin, los países industrializados deben esforzarse por reducir la distancia que los separa de los países en desarrollo. En los países industrializados, los problemas ambientales están generalmente relacionados con la industrialización y el desarrollo tecnológico.

5.- El crecimiento natural de la población plantea continuamente problemas relativos a la preservación del medio, y se deben adoptar normas y medidas apropiadas, según proceda, para hacer frente a esos problemas. De todas las cosas del mundo, los seres humanos son lo más valioso. Ellos son quienes promueven el progreso social, crean riqueza social, desarrollan la ciencia y la tecnología y, con su duro trabajo transforman continuamente el medio humano. Con 
el progreso social y los adelantos de la producción, la ciencia y la tecnología, la capacidad del hombre para mejorar el medio ambiente se acrece cada día que pasa.

6.- Hemos llegado al momento de la historia en que debemos orientar nuestros actos en todo el mundo atendiendo con mayor solicitud a las consecuencias que pueden tener para el medio. Por ignorancia o indiferencia, podemos causar daños inmensos e irreparables al medio terráqueo del que dependen nuestra vida y nuestro bienestar. Por el contrario, con un conocimiento más profundo y una acción más prudente, podemos conseguir para nosotros y para nuestra posteridad unas condiciones de vida mejores en un medio más en consonancia con las necesidades y aspiraciones del hombre. Las perspectivas de elevar la calidad del medio y de crear una vida satisfactoria son grandes. Lo que se necesita es entusiasmo, pero a la vez, serenidad de ánimo, trabajo afanoso, pero sistemático. Para llegar a la plenitud de su libertad dentro de la Naturaleza, el hombre debe aplicar sus conocimientos a forjar, en armonía con ella, un medio mejor. La defensa y el mejoramiento del medio humano para las generaciones presentes y futuras se ha convertido en meta imperiosa de la humanidad que ha de perseguirse al mismo tiempo que las metas fundamentales ya establecidas de la paz y el desarrollo económico y social en todo el mundo, y de conformidad con ellas.

7.- Para llegar a esa meta, será menester que ciudadanos y comunidades, empresas e instituciones, en todos los planos, acepten las responsabilidades que les incumben y que todos ellos participen equitativamente en la labor común. Hombres de toda condición y organizaciones de diferente índole plasmarán, con la aportación de sus propios valores y la suma de sus actividades, el medio ambiente del futuro. Corresponderá a las administraciones locales y nacionales, dentro de sus respectivas jurisdicciones la mayor parte de la carga en cuanto al establecimiento de normas y la aplicación de medidas en gran escala sobre el medio. También se requiere la cooperación internacional con objeto de allegar recursos que ayuden a los países en desarrollo a cumplir su cometido en esta esfera. Y hay un número cada vez mayor de problemas relativos al medio que por ser de alcance regional o mundial o por repercutir en el ámbito internacional común, requerirán de una amplia colaboración entre las naciones y la adopción de medidas para las organizaciones internacionales en interés de todos.

La Conferencia encarece a los gobiernos y a los pueblos que aúnen sus esfuerzos para preservar y mejorar el medio humano en beneficio del hombre y de su posteridad. 


\section{PRINCIPIOS}

Expresa la convicción común de que:

Principio 1.- El hombre tiene el derecho fundamental a la libertad a la igualdad y al disfrute de las condiciones de vida adecuadas en un medio de calidad tal que le permita llevar una vida digna y gozar de bienestar y tiene la solemne obligación de proteger y mejorar el medio para las generaciones presentes y futuras. A este respecto, las políticas que promueven o perpetúan el apartheid, la segregación racial, la discriminación, la opresión colonial y otras formas de opresión y de dominación extranjera quedan condenadas y deben eliminarse.

Principio 2.- Los recursos naturales de la Tierra incluidos el aire, el agua, la tierra, la flora y la fauna y especialmente las muestras representativas de los ecosistemas naturales, deben preservarse en beneficio de las generaciones presentes y futuras, mediante una cuidadosa planificación u ordenación, según convenga.

Principio 3.- Debe mantenerse y siempre que sea posible restaurarse o mejorarse la capacidad de la Tierra para producir recursos vitales renovables.

Principio 4.- El hombre tiene la responsabilidad especial de preservar y administrar juiciosamente el patrimonio de la flora y fauna silvestre y su hábitat que se encuentran actualmente en grave peligro por una combinación de factores adversos. En consecuencia, al planificar el desarrollo económico debe atribuirse importancia a la conservación de la Naturaleza, inclusive la fauna y flora silvestre.

Principio 5.- Los recursos no renovables de la Tierra deben emplearse de forma que se evite el peligro de su futuro agotamiento y que se asegure que toda la humanidad comparte los beneficios de tal empleo.

Principio 6.- Debe ponerse fin a la descarga de sustancias tóxicas o de otras materias a la liberación de calor en cantidades o concentraciones tales que el medio no pueda neutralizadas, para que no se causen daños graves o irreparables a los ecosistemas. Debe apoyarse la justa lucha de los pueblos de todos los países contra la contaminación.

Principio 7.- Los estados deberán tomar todas las medidas posibles para impedir la contaminación de los mares por sustancias que puedan poner en peligro la salud del hombre, dañar los recursos vivos y la vida marina, menoscabar las posibilidades de esparcimiento o entorpecer otras utilizaciones legítimas del mar. 
Principio 8.- El desarrollo económico y social es indispensable para asegurar al hombre un ambiente de vida y trabajo favorable y crear en la Tierra las condiciones necesarias para mejorar la calidad de vida.

Principio 9.- Las deficiencias del medio originadas por las condiciones del subdesarrollo y los desastres naturales plantean graves problemas, y la mejor manera de subsanarlas es el desarrollo acelerado mediante la transferencia de cantidades considerables de asistencia financiera y tecnológica que complementen los esfuerzos internos de los países en desarrollo y la ayuda oportuna que pueda requerirse.

Principio 10.- Para los países en desarrollo, la estabilidad de los precios y la obtención de ingresos adecuados de los productos básicos y las materias primas son elementos esenciales para la ordenación del medio, ya que han de tenerse en cuenta tanto los factores económicos como los procesos ecológicos.

Principio 11.- Las políticas ambientales de todos los estados deberían de estar encaminadas a aumentar el potencial de crecimiento actual o futuro de los países en desarrollo y no deberían coartar ese potencial ni obstaculizar el logro de mejores condiciones de vida para todos, y los estados y las organizaciones internacionales deberían tomar las disposiciones pertinentes con miras a llegar a un acuerdo para hacer frente a las consecuencias económicas que pudieran resultar, en los planos nacional e internacional, de la aplicación de medidas ambientales.

Principio 12.- Deberían destinarse recursos a la conservación y mejoramiento del medio, teniendo en cuenta las circunstancias y las necesidades especiales de los países en desarrollo y cualesquiera gastos que pueda originar a estos países la inclusión de medidas de conservación del medio en sus planes de desarrollo, así como la necesidad de prestarles, cuando lo soliciten, más asistencia técnica y financiera internacional con ese fin.

Principio 13.- A fin de lograr una más racional ordenación de los recursos y mejorar así las condiciones ambientales, los estados deberían adoptar un enfoque integrado y coordinado de la planificación de su desarrollo, de modo que quede asegurada la compatibilidad del desarrollo con la necesidad de proteger y mejorar el medio humano en beneficio de su población.

Principio 14.- La planificación racional constituye un instrumento indispensable para conciliar las diferencias que puedan surgir entre las exigencias del desarrollo y la necesidad de proteger y mejorar el medio. 
Principio 15.- Debe aplicarse la planificación a los asentamientos humanos y a la urbanización con miras a evitar repercusiones perjudiciales sobre el medio y a obtener los máximos beneficios sociales, económicos y ambientales para todos. A este respecto deben abandonarse los proyectos destinados a la dominación colonialista y racista.

Principio 16.- En las regiones en que exista el riesgo de que la tasa de crecimiento demográfico o las concentraciones excesivas de población perjudiquen al medio o al desarrollo, o en que la baja densidad de población pueda impedir el mejoramiento del medio humano y obstaculizar el desarrollo, deberían aplicarse políticas demográficas que respetasen los derechos humanos fundamentales y contasen con la aprobación de los gobiernos interesados.

Principio 17.- Debe confiarse a las instituciones nacionales competentes la tarea de planificar, administrar o controlar la utilización de los recursos ambientales de los estados con el fin de mejorar la calidad del medio.

Principio 18.- Como parte de su contribución al desarrollo económico y social, se debe utilizar la ciencia y la tecnología para descubrir, evitar y combatir los riesgos que amenazan al medio, para solucionar los problemas ambientales y para el bien común de la humanidad.

Principio 19. Es indispensable una labor de educación en cuestiones ambientales, dirigida tanto a las generaciones jóvenes como a los adultos y que preste la debida atención al sector de población menos privilegiado, para ensanchar las bases de una opinión pública bien informada y de una conducta de los individuos, de las empresas y de las colectividades inspirada en el sentido de su responsabilidad en cuanto a la protección y mejoramiento del medio en toda su dimensión humana. Es también esencial que los medios de comunicación de masas eviten contribuir al deterioro del medio humano y difundan, por el contrario, información de carácter educativo sobre la necesidad de protegerlo y mejorado, a fin de que el hombre pueda desarrollarse en todos los aspectos.

Principio 20.- Se deben fomentar en todos los países, especialmente en los países en desarrollo, la investigación y el desarrollo científicos referentes a los problemas ambientales, tanto nacionales como multinacionales. A este respecto el libre intercambio de información científica actualizada y de experiencia sobre la transferencia debe de ser objeto de apoyo y asistencia, a fin de facilitar la solución de los problemas ambientales; las tecnologías ambientales deben ponerse a disposición de los países en vías de desarrollo, en unas condicio- 
nes que favorezcan su amplia difusión sin que constituyan una carga económica para esos países.

Principio 21.- De conformidad con la Carta de las Naciones Unidas y con los principios del derecho internacional, los estados tienen el derecho soberano de explotar sus propios recursos en aplicación de su propia política ambiental y la obligación de asegurarse de que las actividades que se lleven a cabo dentro de su jurisdicción o bajo su control no perjudiquen al medio de otros estados o de zonas situadas fuera de toda jurisdicción nacional.

Principio 22.- Los estados deben cooperar para continuar desarrollando el derecho internacional en lo que se refiere a la responsabilidad y a la indemnización de las víctimas de la contaminación y otros daños ambientales que las actividades realizadas dentro de la jurisdicción o bajo el control de tales estados causen a zonas situadas fuera de su jurisdicción.

Principio 23.- Sin perjuicio de los criterios que puedan acordarse por la comunidad internacional y de las normas que deberán ser definidas a nivel nacional, en todos los casos será indispensable considerar los sistemas de valores prevalecientes en cada país y la aplicabilidad de unas normas que si bien son válidas para los países más avanzados pueden ser inadecuadas y de alto costo social para los países en desarrollo.

Principio 24.- Todos los países, grandes o pequeños, deben ocuparse con espíritu de cooperación y en pie de igualdad de las cuestiones internacionales relativas a la protección y mejoramiento del medio. Es indispensable cooperar, mediante acuerdos multilaterales o bilaterales o por otros medios apropiados, para controlar, evitar, reducir y eliminar eficazmente los efectos perjudiciales que las actividades que se realicen en cualquier esfera puedan tener para el medio, teniendo en cuenta debidamente la soberanía y los intereses de todos los estados,

Principio 25.- Los estados se asegurarán de que las organizaciones internacionales realicen una labor coordinada eficaz y dinámica en la conservación y mejoramiento del medio.

Principio 26.- Es preciso librar al hombre y a su medio de los efectos de las armas nucleares y de todos los demás medios de destrucción en masa. Los estados deben de esforzarse por llegar pronto a un acuerdo en los órganos internacionales pertinentes sobre la eliminación y destrucción completa de tales armas. 


\section{BIBLIOGRAFÍA}

ALTVATER, Elmar. El Precio del Bienestar. Valencia. Edicions Alfons el Magnánim. 1994

AYÚS, A BALLESTER, R. Apuntes de Derecho Ambíental. Sant Vicent del Raspeig (Alicante) Gráficas Díaz. 1996

BALLESTEROS, Jesús. Postmodernidad: Decadencia o Resistencia. Madrid. Edit. Tecnos. 1990.

CARSON, Rachel. Silent Spring. Penguin Books. 1991

CASTAN TOBEÑAS, José. Los Derechos del Hombre. Madrid . Edit. Reus. 1985.

CEE, L'État de I'environnement: Premier raport. Luxemburgo. Edita CEE. 1977

CEOTMA-CIFCA, Calidad de Vida Medio Ambiente y Ordenación del Territorio.

Textos Internacionales Madrid. FUENTES BODELÓN, Fernando. Edit. MOPU 1983.

CLUB DE ROMA, Informes. Ordenados en bibliografía conforme primer autor.

DELAUNAY, Janine. Énquete sur le Club de Rome. En la obra Halte a la

Croissance? Edit. Fayard. Collection Écologie. 1972.

ECHECHURI, Héctor y otros autores. Diez años después de Estocolmo. Desarrollo. Medio Ambiente y Supervivencia. Madrid. Edita CIFCA. 1983.

FRIENDS OF THE WORLD. ONU. La Conferencia de Estocolmo. Sólo una Tierra.

Edit. Vicens Vives. Libros U. Ecología y Sociedad. 1972.

GENDARME. L. La Pobreza de las Naciones. Madrid. Edita B.O.E. 1967.

GONZÁLEZ ALVAREZ, Angel. Manual de Historia de la Filosofía. Edit. Gredos.

1967. Colección; Biblioteca Hispánica de la Filosofía.

LAVILA RUBIRA. J.J. y MENÉNDEZ Mª. José. Todo sobre el Medio Ambiente.

Barcelona. Edita Praxis. 1996.

LÓPEZ BUSTOS, Fco. Luis. La Organización del Medio Ambiente. Univ. Granada.

Cuadernos Cívitas, 1992

MARTÍN MATEO, Ramón. Tratado de Derecho Ambiental. Edita Trivium 1991.

MARTIN MATEO, Ramón. El Hombre: una especie en peligro. Edit. Campomanes. Libros. 1993.

MEADOWS, DENIS L. Los límites del Crecimiento. Primer Informe del Club de Roma. México. Edit. Fondo de Cultura Económica. 1972.

MESAROVIC, M. La Humanidad ante la encrucijada. Segundo Informe del Club de Roma. Madrid. Edita Instituto de Estudios de Planificación. 1975.

ODUM. E. Ecología; Peligra la Vida. Edita B. 1995.

PRIEUR, Michele. Prólogo de Calidad de Vida Medio Ambiente y Ordenación del

Territorio. Madrid CEOTMA-CIFCA 1982. MOPU

ROMERO, José Luis. De Herodoto a Polibio. Edit. Espasa 1951. 
RUSSELL, Bertrand. Has Man a Future? Edit. Penguin Special.

TOFFLER, Alvin. El Shock del Futuro. Plaza y Janés 1971.

WARD, R. y DUBOIS. Una Sola Tierra. México. Edit. FCE. 1972.

YBARRA, Fdo. Introducción al Segundo Informe Club de Roma. IEP. 1975. 